\title{
Numerical Study of Nearshore Hydrodynamics under Storm Wave Conditions in Hujeong Beach, East Coast of Korea
}

\author{
Yeon S. Chang, Korea Institute of Ocean Science and Technology, yeonschang@kiost.ac.kr \\ Jong Dae Do, Korea Institute of Ocean Science and Technology, jddo@kiost.ac.kr \\ Kyungmo Ahn, Handong Global University, kmahn@handong.edu \\ Jae-Youll Jin, Korea Institute of Ocean Science and Technology, jyin@kiost.ac.kr
}

\section{INTRODUCTION}

In this study, we present the results of numerical model study to simulate the hydrodynamic conditions observed in Hujeong Beach in the east coast of the Republic of Kore from December, 2016 to January, 2017 during which several extratropical cyclones hit the area causing extreme wave conditions. Three acoustic instrumentation systems were moored from the coast to a location outside the surf zone where the water depth was $\sim 8 \mathrm{~m}$ to measure waves, currents and suspended sediment concentrations. For the numerical model, we employed the CADMAS-SURF Raynolds-Averaged Navier-Stokes (RANS) model to generate the wave conditions over the region of the field experiment.

\section{FIELD EXPERIMENT}

The wave energy in the east coast of the republic of Korea is usually higher in winter than in summer because extratropical cyclones often develop in this region (Jeong et al., 2016). In order to observe such extreme wave conditions and their effects on the costal hydrodynamics and sediment dynamics, we deployed acoustic instrumentation systems at three different locations from the coast and to a location outside the surf zone where the water depth was $\sim 8 \mathrm{~m}$ during the winter time from December, 2017 to January, 2017. The instruments used include AWAC, ADV, Vector, ADCP, OBS and ABS. One example of the instrument systems that were moored for this experiment is shown in Figure 1(a). During the period, several extratropical cyclones hit the coast of the experimental site, increasing the significant wave heights $(\mathrm{Hs})$ higher than $3 \mathrm{~m}$ with the peak wave period (Tp) longer than $10 \mathrm{sec}$.

\section{NUMERICAL MODEL}

In order to simulate the wave conditions observed in the above section, we employed the CADMAS-SURF model developed by the Port and Harbor Research Institute(PHRI), Japan(2001). The model is characterized by the Volume of Fluid (VOF) method that tracks and locates the free surface by solving additional advection equation for a fluid volume function (Hirt and Nichols, 1981). CADMAS-SURF is a RANS model that solves the $\mathrm{k}-\varepsilon$ equation to for turbulence closure.

The computational domain is a two-dimensional rectangular channel with length of $1,800 \mathrm{~m}$ and height of $15 \mathrm{~m}$. In the right end of the channel, the bed is sloped to gradually reduce water depths. Figure $1(\mathrm{~b})$ shows an example of the CADMAS-SURF model results for the present experiment. The grey-colored contour is the solutions of the fluid volume function equation that shows the surface of the waves that break as they shoal when propagating the shore. The 'P1' - 'P3' in Figure 2(b) are the locations of the instrumentation systems as implemented in the model configuration.

\section{RESULTS}

The observation results show that turbulent kinetic energy (TKE) varied, during one wave period, corresponding to the streamwise flow rate as it had energy peak near the time of maximum flow rate. However, the vertical component of the Reynolds stresses, $-\overline{u^{\prime} w^{\prime}}$ showed peaks near the time of flow reversal. While the model failed to represent the peak of $-\overline{u^{\prime} w^{\prime}}$ at the time of flow reversal. This result indicates that some turbulence quantities are misrepresented by the RANS model, which may cause significant error in the prediction of sediment suspension events from the seabeds.
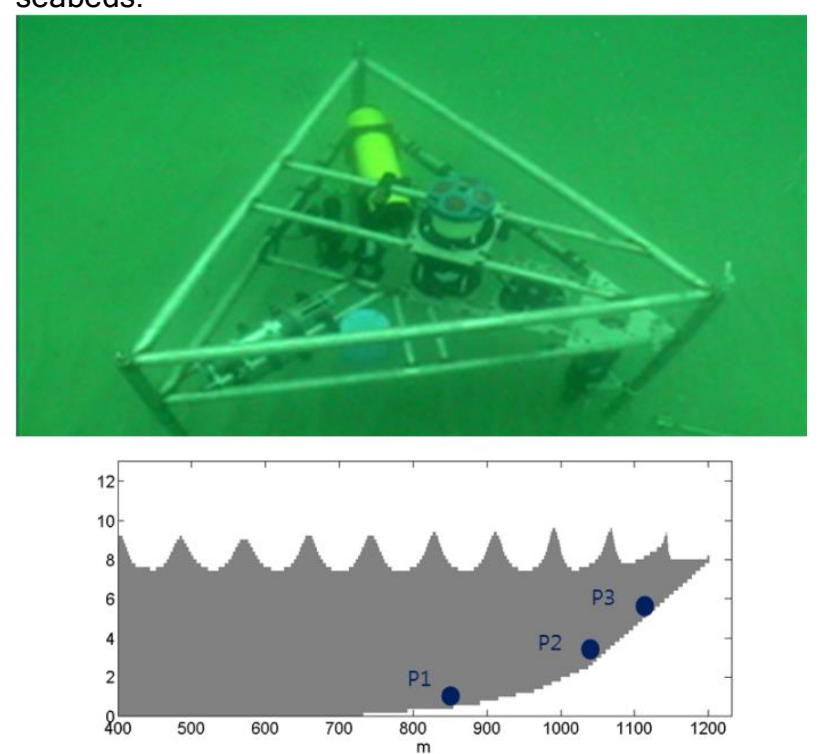

Figure 1 - (a) The instrumentation system located at 'P1'. On the system ADCP, PC-ADP, Vector, LISST-100X, WBL and OBS are installed to measure wave and sediment dynamics near bed, ( b ) CADMAS-SURF model result that shows wave propagation to the coast. 'P1' - 'P3' are the locations of the acoustic instrumentation systems.

In addition, the magnitude of suspended sediment concentration was measured to be higher in the onshore wave phase than in the offshore phase. The analysis of the model results indicates that this asymmetry in the sediment suspension pattern is likely related to the wave skewness.

\section{REFERENCES}

Jeong, W.M., K.-H. Ryu, S.-H. Oh and W.D. Baek (2016) : Trend of storm wave appearance on the east coast analyzed by using long-term wave observation data, J. Korean Soc. Coastal and Ocean Engineers, vol. 28(2), pp.109-115.

PHRI, Coastal Development Institute of Technology (2001) : Research and development of numerical wave channel (CADMAS-SURF), CDIT Library, vol. 12. Hirt, C.W. and Nichols, B.D. (1981) : Volume of fluid (VOF) method for the dynamics of free boundaries, J. Computational Physics, vol. 39, pp. 201-225. 